Revista Tecné, Episteme y Didaxis: TED. Año 2014, Número Extraordinario. ISSN Impreso: 0121-3814, ISSN web: 2323-126

Memorias, Sexto Congreso Internacional sobre Formación de Profesores de Ciencias. 08 al 10 de octubre de 2014, Bogotá

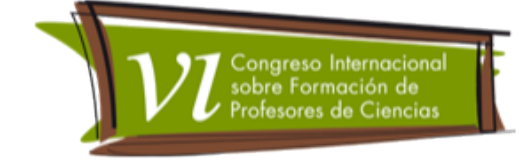

\title{
Diálogos de um saber nem tão elementar: uma análise de perfis conceituais de professores de Física do Ensino Médio da rede pública da região de Bauru-SP, Brasil sobre conceitos de Estrutura da Matéria
}

Prado, G. F.a, de Mello, D. F.b, Gazola, R. J. C.c, Zuliani, S. R. Q. A. '.

Categoria 2. Trabalho de investigação

\section{Resumo}

Este trabalho aborda a construção de perfis conceituais de professores de física sobre o tema Estrutura da Matéria. Por meio da análise fenomenológica e do diálogo com os principais referenciais da área, o discurso dos professores pode ser estabelecido e analisado conforme os saberes científicos atuais.

\section{Palavras Chave}

Estrutura da Matéria, Perfil Conceitual, Formação de Professores.

\section{Objetivos}

As primeiras questões envolvendo a natureza da matéria e suas propriedades apareceram, aproximadamente, há 27 séculos com a cultura grega (Caruso e Oguri, 2006). Nessa época, os homens buscavam a compreensão de um "princípio" natural para todas as coisas. Esse "princípio" pode ser definido como: "aquilo do qual provém, aquilo no qual se concluem e aquilo pelo qual existem e subsistem todas as coisas" (Reale, 1997).

O "princípio" proposto, hoje, sistematiza-se mantendo sua essência, guardadas as devidas restrições, no conceito de elementaridade.

\footnotetext{
a Universidade Estadual Paulista, "Júlio de Mesquita Filho", gustavofprado@outlook.com

b Universidade Estadual Paulista, "Júlio de Mesquita Filho", dfmello@fc.unesp.br

c Universidade Estadual Paulista, "Júlio de Mesquita Filho", rjgazola@yahoo.com.br

d Universidade Estadual Paulista, "Júlio de Mesquita Filho", zuliani@fc.unesp.br
} 
Revista Tecné, Episteme y Didaxis: TED. Año 2014, Número Extraordinario. ISSN Impreso: 0121-3814, ISSN web: 2323-126

Memorias, Sexto Congreso Internacional sobre Formación de Profesores de Ciencias. 08 al 10 de octubre de 2014, Bogotá

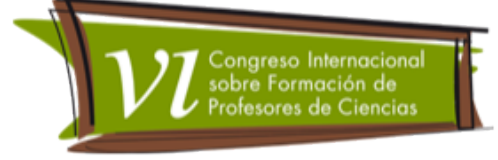

No plano da educação escolar brasileira, os conteúdos que constituem o tema Estrutura Elementar da Matéria (EEM) estão incluídos nos Parâmetros Curriculares Nacionais (PCNs) sob a denominação de Física Moderna e Contemporânea (FMC), nas disciplinas de Física e Química. A importância do estudo e da inserção da FMC no Ensino Médio vem sendo amplamente discutida pela comunidade científica, por profissionais dedicados à criação de materiais didáticos e professores.

Inicialmente, buscamos analisar o modo como os professores abordam e constroem atividades sobre o tema, porém nos deparamos com os seguintes questionamentos que fundamentam este trabalho: qual o significado de um tema tão vasto como Estrutura da Matéria para os professores? Além disso, qual a importância que eles atribuem para esse tema? Resumidamente, poderíamos dizer: O que é a "Estrutura da Matéria", em seu significado mais amplo, para os professores?

Desse modo, a partir do questionamento citado, o objetivo foi levantar os perfis conceituais sobre Estrutura da Matéria apresentados por professores do Ensino Médio da região de Bauru-SP, Brasil, que participaram de um curso de formação continuada desenvolvido durante o ano de 2013. O conhecimento dos perfis conceituais do grupo de professores, além de fornecer informações sobre a construção do conhecimento nos conceitos em que estão envolvidos, permite nortear e delinear ações práticas que sejam mais efetivas na formação continuada desses.

\section{Marco Teórico}

A inserção da FMC no Ensino Médio, além de muito discutida, também possui diversas iniciativas de elaboração de materiais didáticos de apoio a professores de Física do Ensino Médio nos últimos anos (Monteiro et al., 2009; Ostermann e Moreira, 2000; Monteiro, Nardi e Bastos, 2009).

Todos ressaltam que a importância dessa introdução no Ensino Médio, além de promover o conhecimento básico na área de estrutura da matéria, pode contribuir com a tão aclamada relação ciência, †ecnologia e sociedade.

Conforme Terrazan (1992, 1994, apud Orstermann, Moreira, 2000), o ensino de 
Revista Tecné, Episteme y Didaxis: TED. Año 2014, Número Extraordinario. ISSN Impreso: 0121-3814, ISSN web: 2323-126

Memorias, Sexto Congreso Internacional sobre Formación de Profesores de Ciencias. 08 al 10 de octubre de 2014, Bogotá

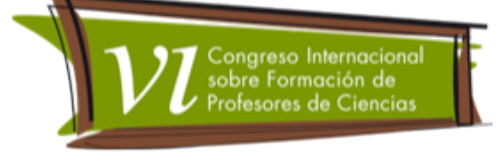

FMC, assim como a atualização do currículo de física são necessários para o entendimento do mundo modificado pelo homem atual e pela necessidade de formar cidadãos conscientes e participativos.

Os Parâmetros Curriculares Nacionais (PCNs) também ressaltam a importância do tema:

A compreensão dos modelos para a constituição da matéria deve, ainda, incluir as interações no núcleo dos átomos e os modelos que a ciência hoje propõe para um mundo povoado de partículas. [...] Ou seja, o estudo de matéria e radiação indica um tema capaz de organizar as competências relacionadas à compreensão do mundo material microscópico. (BRASIL, 2002).

No Estado de São Paulo, Brasil, além da utilização dos livros didáticos, existe uma proposta curricular elaborada pela Secretaria da Educação, órgão a quem compete a administração da educação no estado. Essa proposta tem como finalidade básica nortear o trabalho do professor.

Assim, elaboramos, propusemos e realizamos um curso vinculado à Escola de Formação de Professores do Estado de São Paulo (EFAP), no qual professores que ministram as disciplinas de Física, Química e Biologia no Ensino Médio foram convidados a construir saberes coletivos e individuais sobre o tema. Participaram do curso seis professores de Física. Todos ocupavam cargos efetivos nas escolas. Dois momentos foram fundamentais para a constituição do curso, o primeiro refere-se à sua estruturação, baseada na proposta de ensino por investigação. 0 segundo foi o levantamento de dados utilizando questionários que permitissem analisar os conhecimentos mais próximos do real saber dos sujeitos. De acordo com Cañal et al. (1997), a proposta investigativa tem como principal objetivo a inserção da pessoa como sujeito da aprendizagem; um sujeito capaz de buscar a construção do conhecimento a partir da necessidade de respostas a questões. Os materiais utilizados para este trabalho foram coletados ao longo dos quatro primeiros encontros do curso. A tabela II apresenta uma síntese com as informações mais relevantes dos quatro primeiros encontros e as práticas desenvolvidas. 
Revista Tecné, Episteme y Didaxis: TED. Año 2014, Número Extraordinario. ISSN Impreso: 0121-3814, ISSN web: 2323-126

Memorias, Sexto Congreso Internacional sobre Formación de Profesores de Ciencias. 08 al 10 de octubre de 2014, Bogotá

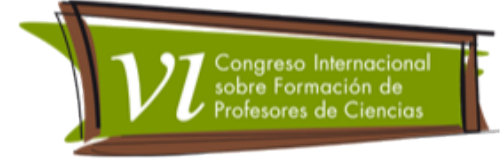

Figura 1. Síntese com as principais informações dos 4 primeiros encontros e práticas desenvolvidas.

\begin{tabular}{|l|l|l|}
\hline $\mathbf{1}^{\circ}$ Encontro & $\begin{array}{l}\text { Apresentação do } \\
\text { curso }\end{array}$ & $\begin{array}{l}\text { Discussão: Apresentação da estrutura do curso, metodologias utilizadas, } \\
\text { datas e atividades a serem realizadas na modalidade presencial e à } \\
\text { distância. }\end{array}$ \\
\hline $\mathbf{2}^{\circ}$ Encontro & Palestra & $\begin{array}{l}\text { Discussão: Panorama sobre as bases da Ciência segundo o pensamento } \\
\text { grego e relações estabelecidas entre as Concepções de Mundo. } \\
\text { Temas discutidos: Constituição da Natureza, Teorias do Conhecimento e } \\
\text { Filosofia da Ciência. }\end{array}$ \\
\hline $\mathbf{4}^{\circ}$ Encontro & $\begin{array}{l}\text { Apresentação } \\
\text { Investigativas }\end{array}$ & $\begin{array}{l}\text { Discussão: A utilização de Metodologias Investigativas em sala de aula. } \\
\text { Discussão: Neurociência cognitiva e educação: bases epistemológicas } \\
\text { Temas discutidos: Modelos conceituais, Analogias, Plasticidade, } \\
\text { Cognição emocional, atenção, memória, raciocínio disjuntivo (indução } \\
\text { do erro), dissonância cognitiva, modelos mentais, campos conceituais. } \\
\text { Atividades propostas: Construção de modelo de partículas elementares, } \\
\text { modelos multissensoriais para o átomo de Bohr e reprodução de sistemas } \\
\text { de interação de partículas. }\end{array}$ \\
\hline
\end{tabular}

Ao final do quarto encontro, foi utilizada uma ficha que propunha a realização de representações para o processo físico de aquecimento e um questionário composto por 5 questões, eles foram nomeados Ficha 01 e Questionário 01, ambos se encontram nos anexos.

\section{Metodologia}

A organização de ideias a respeito de temas da ciência pode ser estruturada através de um continuun, que parte das formas cotidianas de perceber o mundo e chega até uma visão mais próxima do sentido do conhecimento científico. Este continuum ocorre através de eixos que definem uma sequência de construção dos princípios subjacentes ao conhecimento científico (Pozo e Gómez, 2009 pág. 109).

Segundo Pozo e Gómez (2009), "estes eixos possuem a característica de envolver restrições ou tendências do processamento cognitivo natural, no sentido de espontâneo, que é preciso superar em domínios e situações concretas se queremos conseguir interpretá-las de um ponto de vista próximo do científico". Eles são construídos segundo princípios epistemológicos, ontológicos e conceituais. 
Revista Tecné, Episteme y Didaxis: TED. Año 2014, Número Extraordinario. ISSN Impreso: 0121-3814, ISSN web: 2323-126

Memorias, Sexto Congreso Internacional sobre Formación de Profesores de Ciencias. 08 al 10 de octubre de 2014, Bogotá

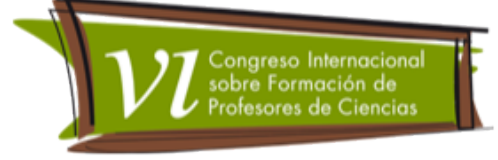

Segundo Greca e Santos (2005), podemos estabelecer analogias através de modelos representacionais: desenhos, imagens e ilustrações. "[...] mas eles em si não podem ser uma analogia, porque a observação do fenômeno quase nunca oferece indícios dos mecanismos internos das reações". Deste modo, propusemos aos professores a Ficha 01 e o Questionário 01 que tinham como objetivo analisar as representações feitos por eles e as explicações dadas concomitantemente.

Devido à grande importância da interpretação qualitativa dos dados, de acordo com o contexto envolvido, à análise filosófica das questões e buscando atingir o objetivo com a maior riqueza possível no detalhamento e tratamento dos dados, optou-se pela análise qualitativa fornecida pela metodologia fenomenológica (Moreira, 2002).

\section{Resultados}

A classificação de princípios em continuuns de ideias permitiu-nos visualizar as primeiras unidades de sentido sobre a questão central da pesquisa. Partimos dos princípios detalhados por Pozo e Gómez (2009) para traçar o perfil de cada um dos sujeitos da pesquisa, mediante o método de análise fenomenológica de Giorgi (Moreira, 2002). Todas as expressões dos sujeitos foram lidas sem interpretação para a busca de um sentido do todo. A partir desta primeira leitura, buscou-se unidades de sentido, relativos à construção dos princípios conceituais, ontológicas e epistemológicas dos sujeitos que correspondem à construção de seu perfil (Pozo e Gómez, 2009).

Após a classificação das ideias, buscou-se a delineação das unidades de sentido e a expressão de seu conteúdo de uma forma mais direta e organizada sobre a questão de pesquisa. Finalizando, sintetizamos as unidades de sentido segundo uma declaração consciente com relação à experiência do sujeito. Esta declaração é chamada de "estrutura da experiência" (Moreira, 2002).

\section{Conclusões}

Com vistas à compreensão do significado do tema Estrutura da Matéria atribuído pelos sujeitos desta pesquisa, pudemos compreender que este grupo, de modo geral, entende-a como um agrupamento de moléculas, que possuem alguma organização e repetição estrutural a pequenas distâncias quando no estado sólido. Quando submetido à variação da energia interna, gradativamente, 
Revista Tecné, Episteme y Didaxis: TED. Año 2014, Número Extraordinario. ISSN Impreso: 0121-3814, ISSN web: 2323-126

Memorias, Sexto Congreso Internacional sobre Formación de Profesores de Ciencias. 08 al 10 de octubre de 2014, Bogotá

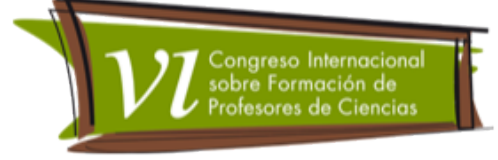

exibem uma desestruturação que segue até o estado gasoso.

Obtivemos dois sujeitos que apresentaram estruturas divergentes dos demais, um deles com um maior grau de estruturação que os outros, utilizando o conceito de átomo (não fazendo referência a modelos específicos) e outro, com menor grau de estruturação, atribuindo características macroscópicas à composição da matéria.

Cinco dos sujeitos realizaram representações idênticas para a água e para o ferro quando solicitados para realizar uma representação de suas "composições reais".

Deste modo, segundo estes dados e as respostas do questionário, entendemos que existem algumas divergências conceituais dos sujeitos com o conhecimento científico atual. Caso as respostas tivessem lidado com representações submicroscópicas, a não exibição de diferenças na composição da matéria seria, em partes, cabível, pois poderiam estar alcançando o conceito de elementaridade, porém as explicações dos sujeitos foram dadas na ordem de grandeza molecular, e em apenas um dos casos atômica. Nestas ordens de grandeza os sujeitos deveriam apresentar e representar diferenças entre as duas estruturas.

Percebemos confusões quanto às relações e representações organizacionais estabelecidas nas diferentes ordens de grandeza (elementar/ atômica/ molecular). Ou seja, um elétron presente em uma molécula de água poderia ser desenhado igual a um elétron presente no átomo de Ferro, porém uma estrutura molecular representativa da água no estado líquido jamais poderia ser igual à do Ferro no estado sólido, por exemplo. As estruturas moleculares das substâncias apresentadas são diferentes. O conceito de um "princípio" organizador, conforme proposto pelas escolas de Mileto, pode existir, mas não na ordem de grandeza apresentada.

A ausência de atividades sobre estes conceitos no currículo, aliada à prática de expressar os fenômenos microscópicos de modo macroscópico cria confusões entre as diferentes realidades. As representações são necessárias, sobretudo quando se tratam de fenômenos não observáveis diretamente, entretanto a dificuldade em impedir que estas analogias (realizadas pelos professores e apresentadas pelos livros didáticos e proposta curricular) se sobreponham aos conceitos pode ser maior que a dificuldade em apresentar os conceitos próprios. 
Revista Tecné, Episteme y Didaxis: TED. Año 2014, Número Extraordinario. ISSN Impreso: 0121-3814, ISSN web: 2323-126

Memorias, Sexto Congreso Internacional sobre Formación de Profesores de Ciencias. 08 al 10 de octubre de 2014, Bogotá

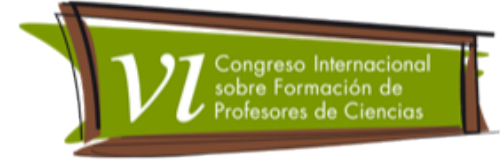

Portanto, é necessário zelo e dedicação na apresentação desses temas por parte dos professores, além da devida atenção e destaque, ainda não existentes na proposta curricular. Esta pesquisa foi essencial para a compreensão futura do ensino, formação e relações que esses sujeitos estabelecem com o currículo de ciências.

\section{Referências bibliográficas}

Brasil (2002). Orientações Educacionais Complementares aos Parâmetros Curriculares Nacionais do Ensino Médio (PCN+): Ciências da Natureza e suas Tecnologias Ministério da Educação e Cultura MEC. Brasília, DF.

Cañal, P; Lledó, A. I.; Posuelos, F. J.; Travé. G. (1997). Investigar en la Escuela: elementos para una enseñanza alternativa. Sevilla: Díada Editorial S.L.

Caruso, F.; Oguri, V.(2006). Física moderna: origens clássicas e fundamentos quânticos. Rio de Janeio: Campus/Elsevier.

Greca, I. M.; Santos, F. M. T. (2005). Dificuldades de generalização e estratégias de modelação em ciências: o caso da física e da química. Investigações em ensino de ciências, v.10. n.1, pág. 31-46.

Minayo M. C. (2007). O desafio do conhecimento: pesquisa qualitativa em saúde. Rio de Janeiro: Abrasco.

Monteiro, M. A.; Nardi, R.; Bastos Filho, J. B. (2009). A sistemática incompreensão da teoria quântica e as dificuldades dos professores na introdução da física moderna e contemporânea no ensino médio. Ciência \& Educação, v. 15, n. 3, pág. 557-580.

Moreira, D. A. (2002). O método fenomenológico na pesquisa. São Paulo: Pioneira Thomson.

Mortimer, E. F. (1996). Construtivismo, Mudança Conceitual e Ensino de Ciências: Para Onde Vamos? Investigações em Ensino de Ciências V1 (1), pg.20 -39.

Ostermann, F.; Moreira, M. A. (2000). Uma revisão bibliográfica sobre a área de pesquisa "física moderna e contemporânea" no Ensino Médio. Investigações em Ensino de Ciências, Porto Alegre, v. 5, n.2, paginação eletrônica. 
Revista Tecné, Episteme y Didaxis: TED. Año 2014, Número Extraordinario. ISSN Impreso: 0121-3814, ISSN web: 2323-126 Memorias, Sexto Congreso Internacional sobre Formación de Profesores de Ciencias. 08 al 10 de octubre de 2014, Bogotá

Pozo, J. I. Gómez, C. (2009). A Aprendizagem e o Ensino de Ciências: do conhecimento cotidiano ao conhecimento científico. Porto Alegre: Artmed.

Reale, G. Antiseri, D. (1997). (2009) História da Filosofia - filosofia pagã antiga. Tradução de Ivo Storniolo. $4^{\circ}$ ed. São Paulo: Paulus,.

\section{Anexos}

Questionário 01/ Ficha 01

Página 01
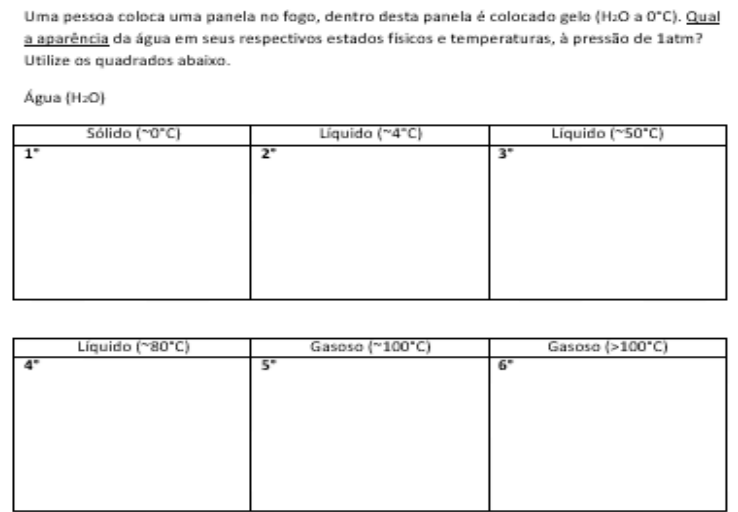

Agora, nos quadrados abaixo, como poderiamos representar do que são canstituidas as seguintes substâncias em seus respectivos estados físicos e temperaturas, à pressão de 1atm na mesma situaçăo descrita acima?

Água $\left(\mathrm{H}_{2} \mathrm{O}\right)$

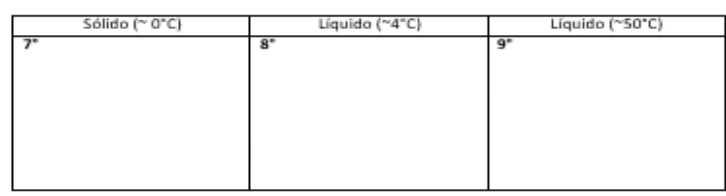

\begin{tabular}{|l|l|l|}
\hline Liquido ( $\left(\mathrm{g0}^{\circ} \mathrm{C}\right)$ & Gasoso $\left({ }^{\prime} 100^{\circ} \mathrm{C}\right)$ & Gasoso $\left(>100^{\circ} \mathrm{C}\right)$ \\
\hline $10^{*}$ & $11^{*}$ & $12^{*}$ \\
& & \\
& & \\
\hline
\end{tabular}

Página 02

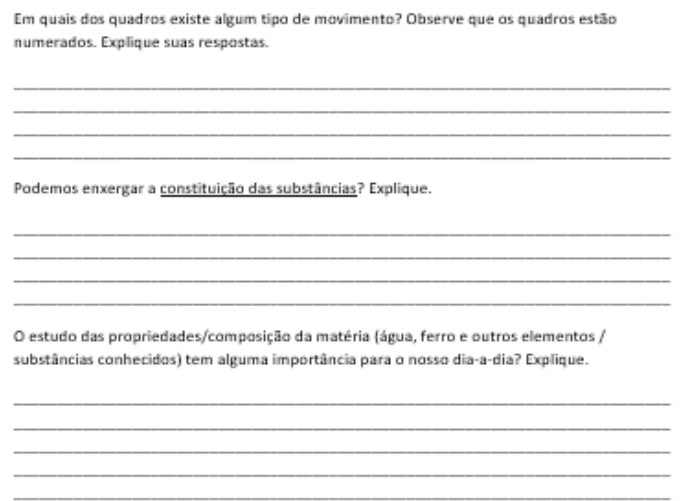


Revista Tecné, Episteme y Didaxis: TED. Año 2014, Número Extraordinario. ISSN Impreso: 0121-3814, ISSN web: 2323-126 Memorias, Sexto Congreso Internacional sobre Formación de Profesores de Ciencias. 08 al 10 de octubre de 2014, Bogotá

Página 03

Esta mesma pessoa coloca agora uma barra de Ferro dentro de um forno capaz de chegar a grandes temperaturas. Qual a aparència do ferro em seus respectivos estados físicos et temperaturas, à pressão de 1 atm?

Ferro (Fe)
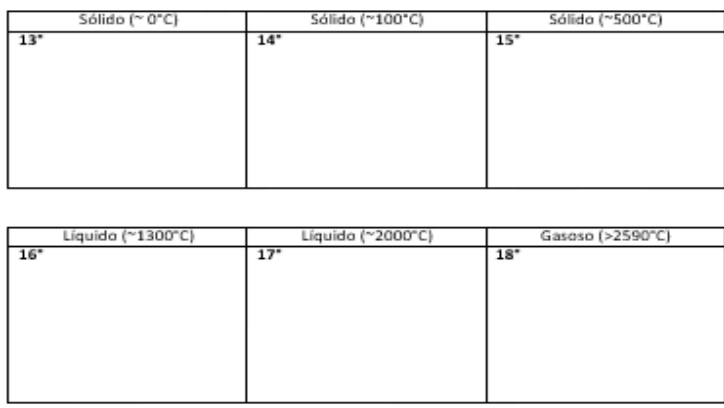

Desenhe agora, na figura atbaixo, como poderiamos representar do que săo canstituidas as seguintes substâncias em seus respectivos estados físicos e temperaturas, à pressão de 1atm: Ferro ( $\mathrm{Fe})$

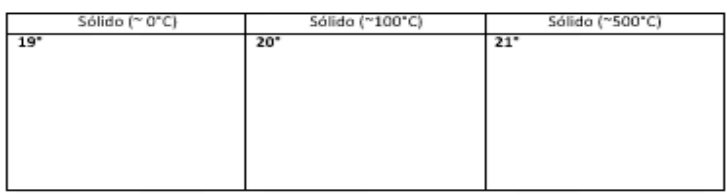

\begin{tabular}{|l|l|l|}
\hline Liquida $\left({ }^{*} 1300^{\circ} \mathrm{C}\right)$ & Liquida $\left({ }^{\circ} 2000^{\circ} \mathrm{C}\right)$ & Gasoso $\left(>25900^{\circ} \mathrm{C}\right)$ \\
\hline & $23^{*}$ & \\
& & \\
& &
\end{tabular}

\section{Página 04}

Em quais dos quadros existe algum tipo de mavimento? Observe que as quadros estão numerados. Explique suas respostas

Até que ponto estes desenhos, imagens $\mathrm{e}$ ilustraç̧̄es realizatos correspondem à realidade? 